\title{
p25/Cyclin-Dependent Kinase 5 Induces Production and Intraneuronal Accumulation of Amyloid $\beta$ In Vivo
}

\author{
Jonathan C. Cruz, ${ }^{1 \star}$ Dohoon Kim, ${ }^{1 \star}$ Lily Y. Moy, ${ }^{1}$ Matthew M. Dobbin, ${ }^{1}$ Xiaoyan Sun, ${ }^{2}$ Roderick T. Bronson, ${ }^{3}$ and \\ Li-Huei Tsai ${ }^{1}$ \\ ${ }^{1}$ Department of Pathology, Harvard Medical School and Howard Hughes Medical Institute, Boston, Massachusetts 02115, and ${ }^{2}$ Center for Neurologic \\ Diseases, Brigham and Women's Hospital, Program in Neuroscience, and ${ }^{3}$ Rodent Histopathology Core, Harvard Medical School, Boston, Massachusetts \\ 02115
}

\begin{abstract}
Aberrant processing of the amyloid precursor protein (APP) and the subsequent accumulation of amyloid $\beta$ (A $\beta$ ) peptide has been widely established as a central event in Alzheimer's disease (AD) pathogenesis. The sequential cleavage steps required for the generation of $A \beta$ are well outlined; however, there is a relative dearth of knowledge pertaining to signaling pathways and molecular mechanisms that can modulate this process. Here, we demonstrate a novel role for p25/cyclin-dependent kinase 5 (Cdk5) in regulating APP processing, A $\beta$ peptide generation, and intraneuronal $\mathrm{A} \beta$ accumulation in inducible $\mathrm{p} 25$ transgenic and compound PD-APP transgenic mouse models that demonstrate deregulated $\mathrm{Cdk} 5$ activity and a neurodegenerative phenotype. Induction of $\mathrm{p} 25$ resulted in enhanced forebrain $\mathrm{A} \beta$ levels before any evidence of neuropathology in these mice. Intracellular A $\beta$ accumulated in perinuclear regions and distended axons within the forebrains of these mice. Evidence for modulations in axonal transport or $\beta$-site APP cleaving enzyme 1 protein levels and activity are presented as mechanisms that may account for the $\mathrm{A} \beta$ accumulation caused by $\mathrm{p} 25 / \mathrm{Cdk} 5$ deregulation. Collectively, these findings delineate a novel pathological mechanism involving aberrant APP processing by p25/Cdk5 and have important implications in AD pathogenesis.
\end{abstract}

Key words: Alzheimer's disease; amyloid $\beta$; BACE1; cdk5; neurodegeneration; p25

\section{Introduction}

The sequential cleavage of amyloid precursor protein (APP) by two aspartyl proteases, referred to as the $\beta$ - and $\gamma$-secretases, yields amyloid $\beta(\mathrm{A} \beta)$ peptides of two principal lengths, $\mathrm{A} \beta_{40}$ and $\mathrm{A} \beta_{42}$ (Selkoe and Schenk, 2003). Accumulation of $\mathrm{A} \beta_{42}$, the longer form of $A \beta$ that more readily aggregates into amyloid plaques, can elicit a multistep cascade that disrupts neuronal homeostasis and causes the aberrant activation of kinases. These alterations in kinase activities ultimately result in neurofibrillary tangle formation and neuronal loss. This "amyloid hypothesis" has been supported by the identification of genetic mutations affecting $\mathrm{A} \beta$ generation in familial Alzheimer's disease (AD), as

\footnotetext{
Received 0ct. 15, 2005; accepted Sept. 6, 2006.

This work is partially supported by National Institutes of Health Grant NS051874 and a grant from Alzheimer's Research Consortium (L.-H.T.). L.-H.T. is an investigator of the Howard Hughes Medical Institute and is affiliated with the RIKEN-Massachusetts Institute of Technology Neuroscience Research Center. We thank Dennis Selkoe and Charles Glabe for kindly providing antibodies, Hui Zheng for APP ${ }^{-1-}$ brains, Jie Shen for help with A $\beta$ measurement, Maria Ericksson for assistance with immunoelectron microscopy, and Sangki Park and Benjamin Samuels for help with manuscript preparation.

*J.C.C. and D.K. contributed equally to this work.

Correspondence should be addressed to Li-Huei Tsai at her present address: Picower Institute for Learning and Memory, Department of Brain and Cognitive Sciences, Massachusetts Institute of Technology, Boston, MA 02139. E-mail: Ihtsai@mit.edu.

J. C. Cruz's present address: Merck Research Laboratories, 33 Avenue Louis Pasteur, Boston, MA 02115.

D. Kim's, L. Y. Moy's, and M. M. Dobbin's present address: Picower Institute for Learning and Memory, Department of Brain and Cognitive Sciences, Massachusetts Institute of Technology, Boston, MA 02139.

DOI:10.1523/JNEUROSCI.3133-06.2006

Copyright $\odot 2006$ Society for Neuroscience $\quad$ 0270-6474/06/2610536-06\$15.00/0
}

well as a large body of in vitro and in vivo research (Gotz et al., 2001; Lewis et al., 2001; Oddo et al., 2003).

Cyclin-dependent kinase 5 (Cdk5) requires association with its neuron-specific regulatory subunit p35 for catalytic activation (Tsai et al., 1994). Neurotoxic stresses induce calcium influx, calpain activation, and cleavage of p35 to p25, which in turn results in aberrant activation of Cdk5 and increased phosphorylation of pathological substrates such as tau. A number of groups have reported a significant increase in p 25 levels or C $\mathrm{dk} 5$ activity in human AD brains (Lee et al., 1999; Patrick et al., 1999; Swatton et al., 2004). Additional support for a role of p25/Cdk5 in AD pathogenesis is derived from p 25 transgenic ( $\mathrm{Tg}$ ) mouse models that display progressive neurodegeneration and neurofibrillary tangle pathology (Cruz et al., 2003; Noble et al., 2003).

We previously created bitransgenic mice (Cruz et al., 2003) that use the tetracycline-controlled transactivator system to inducibly overexpress human p25 under the control of the calcium/ calmodulin-dependent protein kinase II (CK) promoter. The CK-p25 Tg mice are initially raised on a doxycyclinesupplemented diet from conception to 5-8 weeks after birth; after brains have developed normally, the mice are subjected to a doxycycline-free diet, which results in forebrain-specific expression of $\mathrm{p} 25$. As described previously, aberrant activation of $\mathrm{p} 25 /$ Cdk5 results in neurodegeneration (e.g., brain atrophy, astrogliosis, and tau phosphorylation), which continues to progress over several weeks and results in substantial neuronal loss and neurofibrillary tangle pathology (Cruz et al., 2003). However, the pre- 

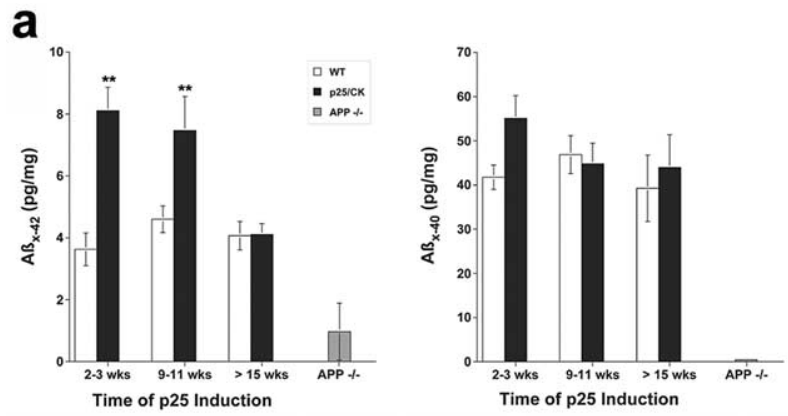

b
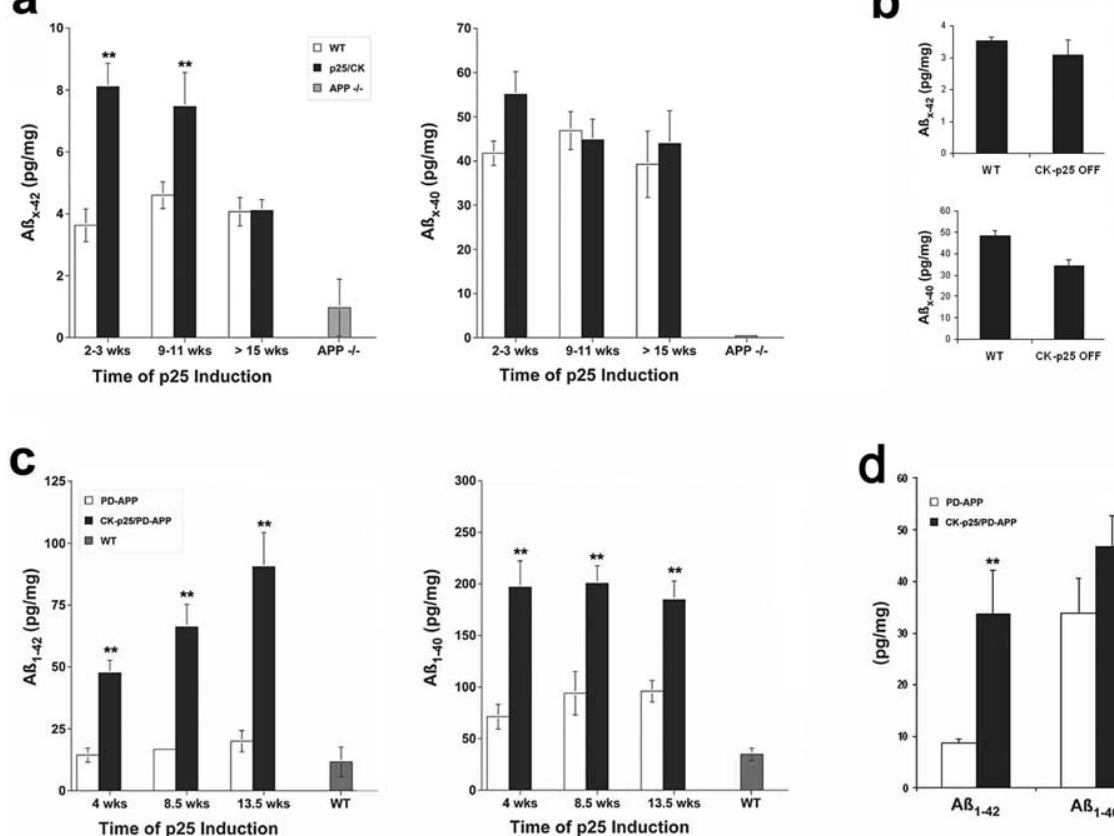
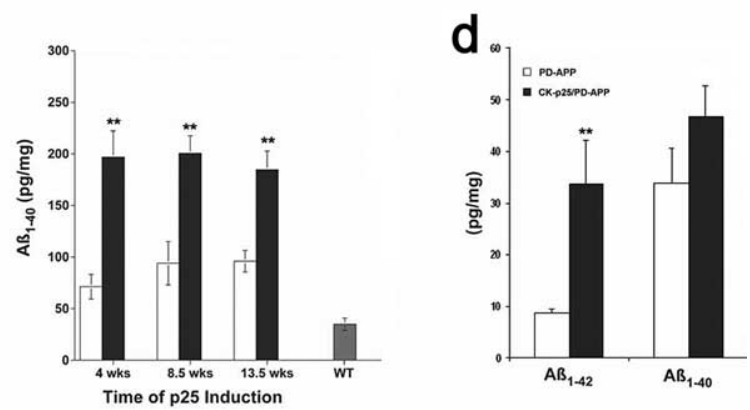

Figure 1. Increased $A \beta$ levels in $p 25 \mathrm{Tg}$ mice. $\boldsymbol{a}, A \beta_{x-42}$ and $A \beta_{x-40}$ levels were determined by ELISA using capture antibodies $21 F 12$ and $2 G 3$ that specifically recognize mouse $A \beta_{x-42}$ and $A \beta_{x-40}$, respectively. Data are mean \pm SEM values for WT $(n=5)$ and $\mathrm{CK}-\mathrm{p} 25 \mathrm{Tg}(n=5)$ mice. APP ${ }^{-1-}$ indicates APP knock-out brain lysate used as negative control. $\boldsymbol{b}, \mathrm{A} \beta$ levels are not increased in uninduced p25 Tg mice. Data are mean \pm SEM values for WT $(n=3)$ and CK-p25 $\mathrm{Tg}(n=3)$ mice. $\mathrm{A} \beta_{\mathrm{x}-42}$ levels were unchanged, whereas there was a small but significant decrease in $A \beta_{x-40}$ levels in uninduced p25 $\mathrm{Tg}$ mice compared with WT. $c$, Human A $\beta$ levels in PD-APP/CK-p25 mice were determined by ELISA. Data are mean \pm SEM values for PD-APP $(n=3)$ and CK-p25/PD-APP $(n=3)$ mice. $\boldsymbol{d}$, Insoluble human A $\beta$ levels were determined by ELISA from RIPA-insoluble pellet fraction from forebrain lysates of PD-APP and CK-p25/PD-APP mice induced for 8 weeks. Data are mean \pm SEM values for PD-APP $(n=3)$ and CK-p25/PD-APP $(n=3)$ mice. ${ }^{* *} p<0.005$, by two-tailed, unpaired Student's $t$ test.

cise mechanisms that precede these neurotoxic events have yet to be elucidated.

In this study, we report that $\mathrm{p} 25$ production positively impacts $\mathrm{APP}$ processing and $\mathrm{A} \beta$ production in vivo before any observable neurodegeneration in p25 Tg mouse models. In addition, we show that $\mathrm{A} \beta$ accumulates intracellularly in p25-expressing neurons. These observations highlight a novel role for p25/Cdk5 in modulating $\mathrm{A} \beta$ in the pathogenesis of neurodegenerative diseases such as AD.

\section{Materials and Methods}

Mice. CK-p25 mice were subjected to postnatal, forebrain-specific p25 induction (Cruz et al., 2003). PD-APP/CK-p25 mice were generated by crossing the CK-p25 mice with PD-APP mice (mice that express human APP containing the V717F mutation under the PDGF promoter) (Games et al., 1995). Individual mouse lines were backcrossed for multiple generations to obtain a homogeneous C57BL/6J background. Littermates and same-sex mice were used for comparison whenever possible. All transgenes were heterozygous. Mice were induced for indicated periods at 5-8 weeks of age.

Immunogold electron microscopy, immunohistochemistry, and immunoblot analysis. 4G8 (Signet Laboratories, Dedham, MA), 6E10 (Zymed Laboratories, South San Francisco, CA), M1 (Charles Glabe, University of California, Irvine, CA), R1736 and R1282 (Dennis Selkoe, Center for Neurologic Diseases, Boston, MA), heavy chain neurofilament (NF-H) (Sigma, St. Louis, MO), and $\beta$-site APP cleaving enzyme 1 (BACE1) (Chemicon, Temecula, CA) were used for immunohistochemistry or immunoelectron microscopy. BACE1 (Oncogene, Cambridge, MA) and CT695 (Zymed Laboratories) were used for immunoblot analysis.

For immunogold labeling, mice were anesthetized, perfused, and fixed in $4 \%$ paraformaldehyde; subiculum and adjacent white matter were processed (Cruz et al., 2003). For immunohistochemistry, paraffin sec- tions of mouse brains were subjected to antigen retrieval and subsequently analyzed (Cruz et al., 2003). For immunoblots, mouse forebrain lysates were analyzed (Cruz et al., 2003).

$A \beta$ ELISA. Total $\mathrm{A} \beta$ pools were solubilized with $5 \mathrm{~m}$ guanidine $\mathrm{HCl} / 50 \mathrm{~mm}$ Tris from mouse forebrain extracts. Mouse forebrain $\mathrm{A} \beta$ was analyzed by ELISA (Beglopoulos et al., 2004); human $\mathrm{A} \beta$ was analyzed by ELISA according to the instructions of the manufacturer (BioSource, Camarillo, CA).

\section{Results}

Increased $\mathrm{A} \beta$ levels in p $25 \mathrm{Tg}$ mouse models

To determine whether $\mathrm{p} 25 / \mathrm{Cdk} 5$ can regulate $\mathrm{A} \beta$ in vivo, we examined endogenous mouse total $\mathrm{A} \beta_{\mathrm{x}-42}$ and $\mathrm{A} \beta_{\mathrm{x}-40}$ levels in forebrain lysates from $\mathrm{CK}-\mathrm{p} 25 \mathrm{Tg}$ mice induced postnatally for various periods of time. Using $A \beta$ capture antibodies specifically recognizing mouse $A \beta$ species but not APP holoprotein or APP C-terminal fragments, we found a significant increase in total $\mathrm{A} \beta_{\mathrm{x}-42}$ levels in $\mathrm{CK}-\mathrm{p} 25$ mice after as early as $2-3$ weeks of p25 induction compared with wild-type (WT) mice (Fig. 1a), whereas uninduced CK-p25 did not display an increase (Fig. 1b). After this period of postnatal induction of $\mathrm{p} 25$, no signs of neurodegeneration with regards to brain atrophy, neuronal loss, or tau pathology can be detected in these mice (Fischer et al., 2005). After $>15$ weeks of p25 induction, when most of the degeneration had occurred, $\mathrm{A} \beta_{\mathrm{x}-42}$ levels were no longer elevated in the $\mathrm{CK}-\mathrm{p} 25$ mice. Total $\mathrm{A} \beta_{\mathrm{x}-40}$ levels were not significantly elevated in these mice at all induction periods analyzed. To investigate whether p 25 can affect human $A \beta$, we crossed CK-p25 mice with PD-APP mice, which express human APP containing the V717F mutation under the PDGF promoter (Games et al., 1995), and analyzed human total $\mathrm{A} \beta_{1-42}$ and $\mathrm{A} \beta_{1-40}$ levels in the compound CK-p25/PD-APP Tg mice. We found that both $\mathrm{A} \beta_{1-42}$ and $\mathrm{A} \beta_{1-40}$ levels were significantly increased compared with single PD-APP mice at all induction periods analyzed (Fig. 1c). Additional analyses of $A \beta$ extracted from radioimmunoprecipitation assay (RIPA)-insoluble pellet fractions demonstrated a dramatic increase in insoluble $\mathrm{A} \beta_{1-42}$ levels in CK-p25/PD-APP mice compared with control mice (Fig. $1 d$ ). These results demonstrate that p25 positively impacts not only levels of endogenous mouse $\mathrm{A} \beta$ but also human $\mathrm{A} \beta$ derived from mutant APP and may preferentially modulate an insoluble $\mathrm{A} \beta_{1-42}$ pool.

\section{Intraneuronal $\mathrm{A} \boldsymbol{\beta}$ accumulation}

To further elucidate the pool of $\mathrm{A} \beta$ that may be modulated by p25/Cdk5, we conducted immunohistochemical studies in the p25 Tg mouse models. Using an antibody that recognizes amino acids $17-24$ of $\mathrm{A} \beta$, we detected a significant increase in 4G8 immunoreactivity in neurons within the cerebral cortex (Fig. 2a) and other brain regions of $\mathrm{CK}-\mathrm{p} 25$ mice relative to control mice. Antibody 6E10, which recognizes human $\mathrm{A} \beta$ and its precursor forms, showed more intense intraneuronal immunoreactivity in the compound CK-p25/PD-APP mice compared with control mice (Fig. 2b). Immunoreactivity against $\mathrm{M} 1$, an oligomer- 
specific antibody that recognizes the primary toxic species of amyloids (Kayed et al., 2003), was observed both intracellularly and extracellularly (Fig. 2b). The marked increases in 6E10 and M1 immunoreactivities were not attributable to significant increases in APP holoprotein (Fig. 2b).

To examine intraneuronal $\mathrm{A} \beta$ accumulation at an ultrastructural level, we performed immunoelectron microscopy on p25 Tg mice using various $A \beta$ antibodies. In both mouse models, $4 \mathrm{G} 8$ immunogold particles localized to perinuclear aggregations that appeared fibrillar in nature, had a diameter of $\sim 10 \mathrm{nM}$, and dominated the soma (Fig. $2 c$, middle, right). Furthermore, these accumulations were more extensive and frequent in CK-p25/PD-APP mice than CK-p25 mice and highly immunoreactive toward the human-specific $\mathrm{A} \beta$ antibodies R1282, 6E10, and, to a lesser degree, M1 (Fig. 2d). Many of these perinuclear accumulations were labeled by a neurofilament antibody (NF-H), indicating a neuronal origin and suggesting association with neurofilament networks (Fig. $2 d$ ). The $\mathrm{A} \beta$ aggregations were also closely associated with degenerative nuclear morphology (Fig. 2c,e,f). Compared with neurons without these $A \beta$ aggregations, which displayed relatively large nuclei with little or no chromatin condensation and an organelle-rich cytoplasm (Fig. $2 c$, left), neurons with visible $A \beta$ aggregations had shrunken nuclei with severe and clearly outlined chromatin condensation (Fig. $2 c$, middle and right; quantified in $e, f$ ). No evidence of these aggregates was found in age-matched PD-APP or WT control mice (data not shown), providing additional evidence that p25 may preferentially modulate the insoluble pool of $A \beta$. In addition, whereas fibril-like accumulations were not observed in cortical neurons by electron microscopy, 6E10 intraneuronal staining was correlated with degenerative nuclear morphology (Fig. 2g). These results suggest that intraneuronal accumulation of $A \beta$ may be one crucial mechanism involved in p25/ Cdk5-mediated neurodegeneration.

\section{$A \boldsymbol{\beta}$ accumulation in distended axons} Within the fiber tracts of the dorsal hippocampal commissure of $\mathrm{p} 25 \mathrm{Tg}$ mice, we detected distended axons that displayed intense 4G8 immunoreactivities (Fig. 3A). The extent of 4G8-swollen axons was clearly increased in CK-p25/PD-APP mice compared with CK-p25 mice and was not observed in age-matched control mice (Fig. 3A). In CK-p25 mice, swollen axons were easily identified by histochemical a
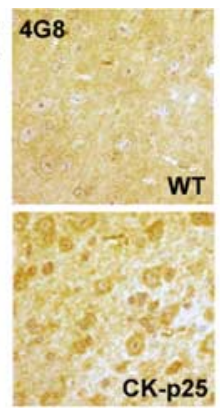
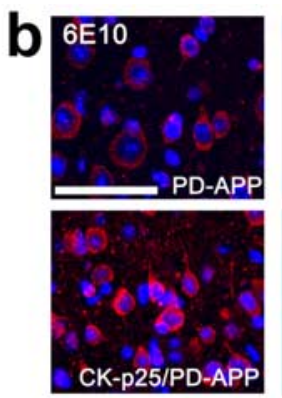
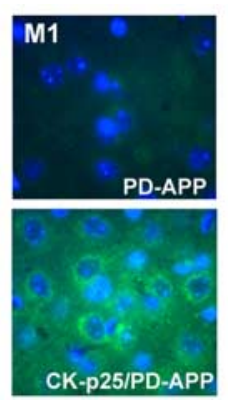
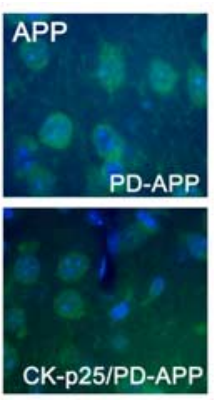

\section{C}
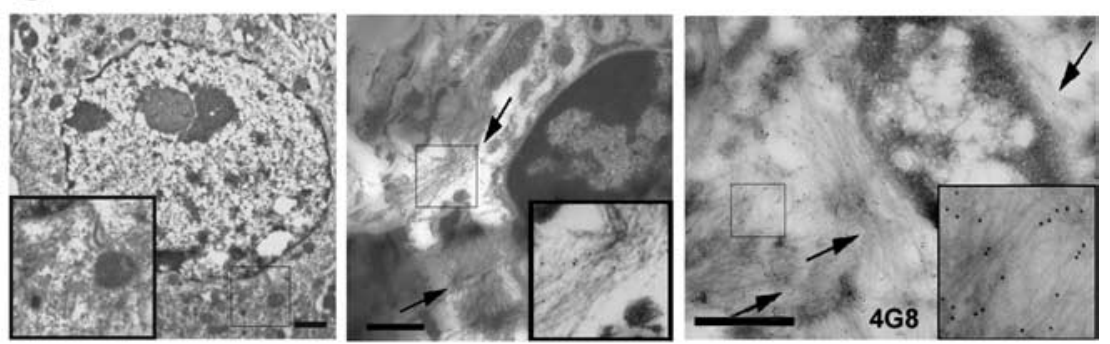

d
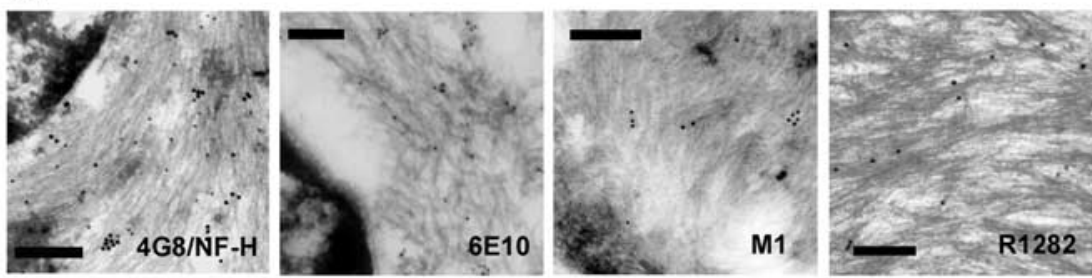

\section{e}
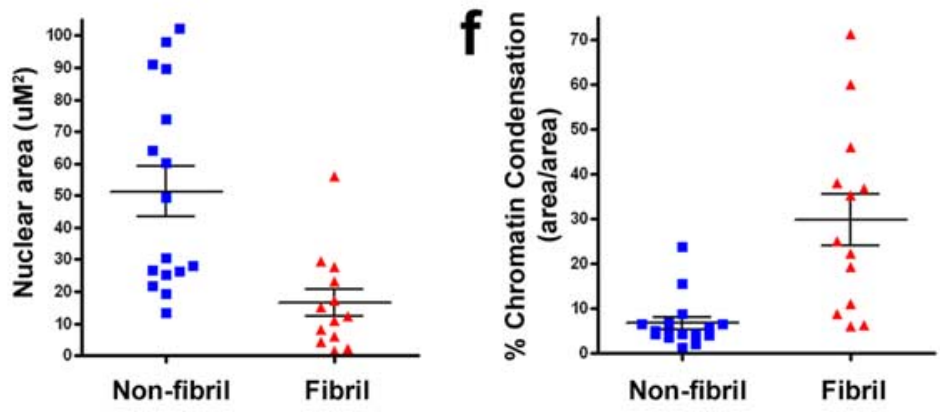

\section{g}

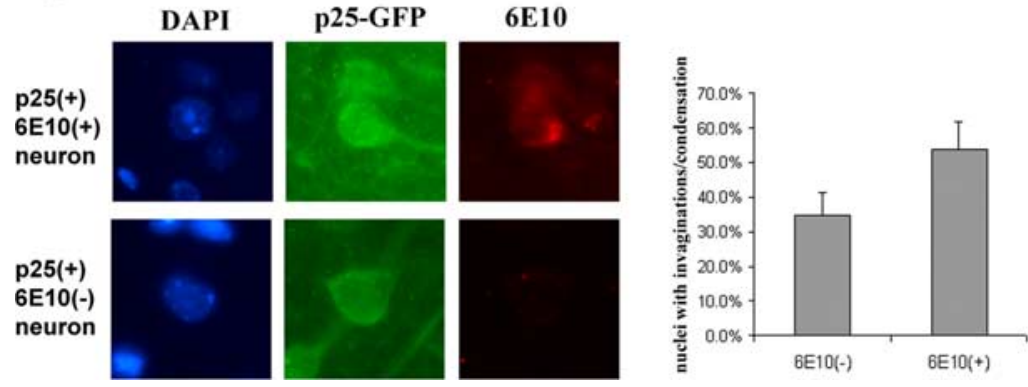

Figure 2. Intraneuronal accumulation of $A \beta$ in $25 \mathrm{Tg}$ mice in perinuclear pools. $\boldsymbol{a}$, Increased 468 immunoreactivity was found in cell bodies of the cortex of CK-p25 mice compared with WT controls at 8 weeks of induction. $\boldsymbol{b}$, Intraneuronal $A \beta$ accumulation was detected by $6 \mathrm{E} 10$ and $\mathrm{M} 1$ antibodies. APP holoprotein levels, as detected by the R1736 APP N-terminal antibody, were similar between CK-p25/PD-APP and PD-APP mice. Cortex of mice induced for 8 weeks are shown. $c$, Immunoelectron microscopy with the $4 G 8$ antibody demonstrate the aggregation of intraneuronal $A \beta$ in fibril-like structures adjacent to the nucleus in CK-p25 mice (middle, arrows), which were more extensive and frequent in CK-p25/PD-APP mice (right, arrows). Also shown is a neuron without 4G8 immunoreactivity (left). Inset is a magnification of the area outlined by the smaller box. $\boldsymbol{d}$, First panel, Perinuclear $A \beta$ 

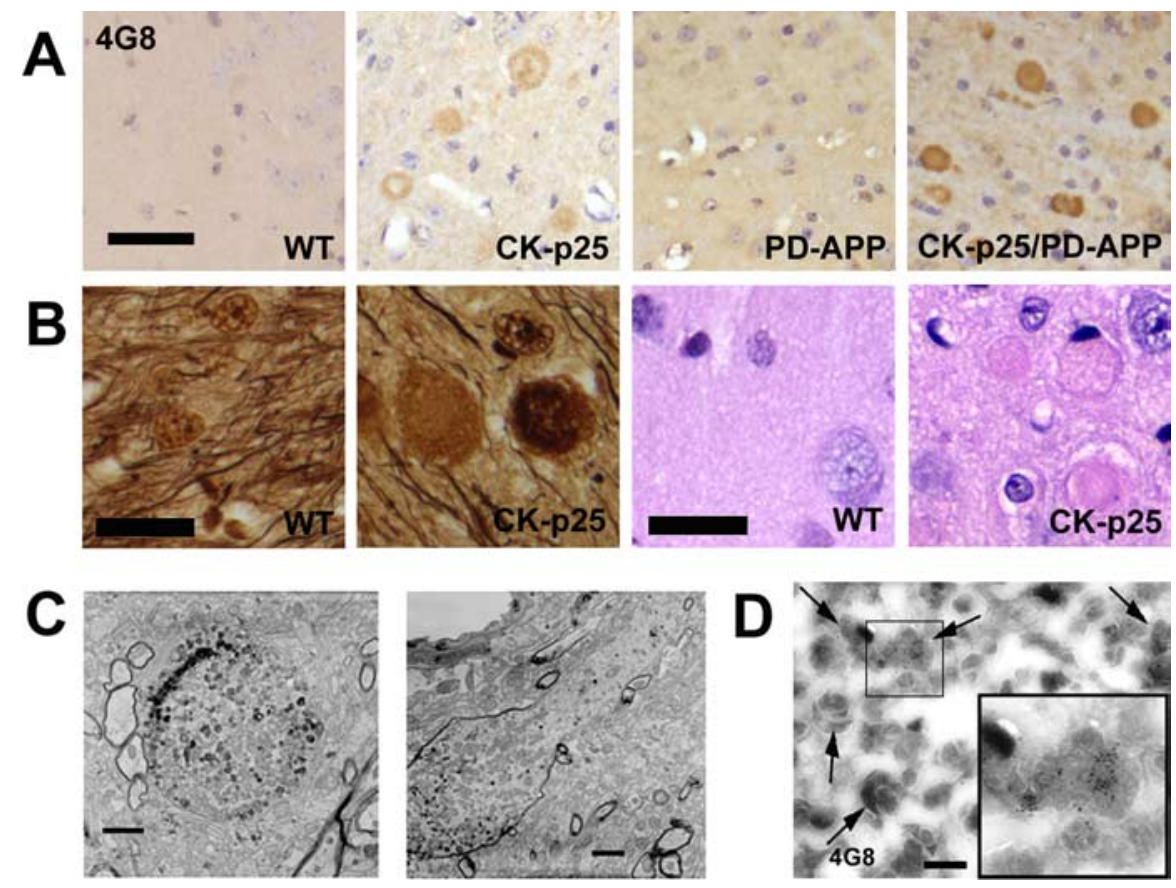

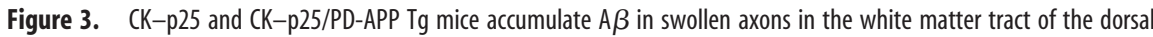
hippocampal commissure. $\boldsymbol{a}, 4 \mathrm{G} 8$ immunoreactivity was observed in swollen axons in (K-p25 mice (second panel) and to a greater extent in PD-APP/CK-p25 mice (fourth panel) induced for 8 weeks but not in WT (first panel) and PD-APP (third panel) control mice. $\boldsymbol{b}$, Swollen axons were clearly visible by Bielchowsky silver stain, showing various degrees of impregnation from orange to black (second panel) and by hematoxylin and eosin staining, appearing as well defined, eosinophilic structures (fourth panel) in (K-p25 mice. Swollen axons were not detected in age-matched WT (first and third panels) or PD-APP (data not shown) controls. c, Electron microscopy of the swollen axons, shown in cross section (left panel) and longitudinal sections (right panel), revealed an amassment of organelles and vesicles and deteriorating myelination. Electron micrographs are from CK-p25 mice induced for 9 weeks. d, $4 \mathrm{G} 8$ immunoelectron micrographs revealed immunoreactive clusters in electron-dense, vesicular structures within swollen axons in CK-p25/PD-APP mice induced for 12 weeks. Aggregations are indicated by arrows. Inset is a magnification of area outlined by the smaller box. Scale bars, $200 \mathrm{~nm}$.

staining (Fig. 3B). At an ultrastructural level, the spheroids displayed an amassment of mitochondria and electron-dense vesicular structures (Fig. 3C). Immunogold electron microscopy revealed strong $4 \mathrm{G} 8$ staining in the vesicular organelles within distended axons of CK-p25/PD-APP mice (Fig. 3D). These organelles may be early endosomes or multivesicular bodies, which are known sites for intracellular A $\beta$ generation (Haass et al., 1992; Ferreira et al., 1993). The presence of distended axons in the p25 Tg mouse models is highly suggestive of axonal transport dysfunction, which has been demonstrated to be mechanistically involved in the accumulation of $\mathrm{A} \beta$ (Stokin et al., 2005).

\section{Increased BACE1 levels and aberrant APP processing}

Another mechanism that may account for enhanced $A \beta$ levels caused by $\mathrm{p} 25 / \mathrm{Cdk} 5$ is aberrant APP processing. To address this

$\leftarrow$

aggregates were also immunoreactive toward NF-H (smaller immunogold particles) and 4G8 (larger particles). In the CK-p25/ PD-APP mice, aggregates stained positive for the $A \beta$-related antibodies 6 E10 (second panel), M1 (third panel), and R1282 (fourth panel). Nuclear area $(\boldsymbol{e})$ and percentage occupied by condensed chromatin $(\boldsymbol{f})$ were calculated for neurons without $(n=16$; blue squares) and with ( $n=13$; red triangles) perinuclear $A \beta$ aggregations from immunoelectron micrographs from CK-p25/PD-APP mice. Results are displayed as a scatter plot, with error bars indicating SEM. Results were statistically significant ( $p=0.0011$ for $\boldsymbol{e} ; p=0.0002$ for $\boldsymbol{f}$ ) according to two-tailed, unpaired Student's $t$ test. For $\mathbf{c}$ and $\boldsymbol{d}$, immunoelectron microscopy was performed on 12 week induced CK-p25 and CK-p25/PD-APP mice, analyzing the subiculum region, which showed the greatest 4G8 staining (data not shown). Scale bar, 500 nm. g, Cortical neurons from 5-10 week CK-p25/PD-APP mice $(n=3)$ expressing p25-GFP with or without intraneuronal 6E10 staining were scored in a blinded manner for degenerative nuclear morphology, as indicated by condensed or invaginated nuclei. A minimum of 2006 E10-positive and 2006E10-negative neurons were counted for each animal. Shown in the left are an example p25-positive, 6E10-positive neuron and a p25-positive, 6E10-negative neuron; the right indicates total quantification. DAPI, 4',6' -Diamidino-2-phenylindole. possibility, we examined the levels of APP cleavage enzymes in forebrain lysates derived from $\mathrm{CK}-\mathrm{p} 25$ mice. Although levels of presenilin-1 did not appear to change (data not shown), there was a significant increase in protein levels of the $75 \mathrm{kDa}$ form of BACE1 (Fig. 4a) after 2-3 weeks of p25 induction. Furthermore, the elevation in BACE1 protein levels was subsequently followed by increased $\beta$-secretase activity as evidenced by significant increases in APP C-terminal fragments, C89 and C99, but not APP holoprotein, in 5-8 week induced $\mathrm{p} 25 \mathrm{Tg}$ mice relative to control mice (Fig. 4b,c). BACE1 and APP C-terminal fragments were concomitantly increased at 5 weeks of induction (Fig. 4e). It is important to note that APP C-terminal fragment accumulation is also dependent on additional factors such as phosphorylation, stability, and $\gamma$-secretase processing. The increase in BACE1 levels was further confirmed by immunohistochemical analysis in neurons within the cortex (Fig. $4 d$ ) and other regions of p25 transgene expression such as the hippocampus (data not shown). The majority of neurons with increased BACE1 staining were also green fluorescent protein (GFP) positive, suggesting a cell-autonomous effect of p25 transgene expression. These results imply that enhanced BACE1 levels and activity can contribute to aberrant APP processing and increased $\mathrm{A} \beta$ levels regulated by p25/Cdk5.

\section{Discussion}

previously reported the characterization of an inducible p25 model that displays progressive neurodegeneration (Cruz et al., 2003). In this study, we extend these findings to demonstrate that deregulated p25/Cdk5 activity can also lead to aberrant APP processing and in vivo. We observe significant cen in endogenous mouse and mutant human $A \beta$ levels in CK-p25 and CK-p25/PD-APP Tg mouse models, respectively. Our cumulative findings establish that the neuropathological hallmarks of AD, namely aberrant APP processing, tau pathol, and neuronal loss, can all develop from p25/Cdk5 deregulation and validate the implementation of these mice as viable animal models to further elucidate the molecular relationships among these pathological events.

Intracellular $A \beta$ is one species of the APP pool that appears to be directly impacted by $\mathrm{p} 25 / \mathrm{Cdk} 5$. Intraneuronal $\mathrm{A} \beta$ was first suggested to play an important role in $\mathrm{AD}$ more than a decade ago (LaFerla et al., 1995). More recently, intracellular $\mathrm{A} \beta_{42}$ has been detected in $\mathrm{AD}$ vulnerable regions in human brains (Gouras et al., 2000) and Tg animal models of AD (Oddo et al., 2003; Casas et al., 2004; Billings et al., 2005) and has been 
shown to be closely associated with neuronal loss (Casas et al., 2004) and cognitive decline (Billings et al., 2005). In our studies, using both biochemical and microscopy approaches, we find an accumulation of intracellular $\mathrm{A} \beta$ in our p25 Tg mouse models. Not only do these mice display increases in total $\mathrm{A} \beta$ levels, they also exhibit significant accumulations of insoluble $\mathrm{A} \beta$ levels with a preferential increase for the more toxic $\mathrm{A} \beta_{1-42}$ compared with $\mathrm{A} \beta_{1-40}$ species. At an ultrastructural level, these intracellular accumulations closely resemble amyloid fibrils (Masliah et al., 1996; Van Dorpe et al., 2000) and appear to be closely associated with neurons that display a degenerative nuclear morphology. Importantly, according to our recent publication (Fischer et al., 2005), significant impairments in learning and memory are observed starting at 5-6 weeks after p25 induction, which corresponds to the timeframe in which intraneuronal accumulations are first detected by $4 \mathrm{G} 8$ immunostaining. Because these accumulations occur in the absence of extracellular plaques, our cumulative results provide support for a pathological consequence of intraneuronal $\mathrm{A} \beta$ accumulation.

Cdk5 has been shown to have direct impacts on components of transport machinery such as the lis $1 /$ nudel/dynein complex and cytoskeletal proteins, such as tau or neurofilament. As such, disruptions in Cdk5 activity may adversely affect axonal transport (Morfini et al., 2004), which may in turn contribute to the intraneuronal build-up of $\mathrm{A} \beta$. The presence of 4G8-immunoreactive distended axons in the p25 Tg mouse models further suggests a link between defective transport and enhanced $\mathrm{A} \beta$ production. In support of this notion, a recent study reports the presence of swollen axons in early Braak stage $\mathrm{AD}$ brains and in vivo upregulation of $\mathrm{A} \beta$ production after impairment of transport by a $50 \%$ reduction in kinesin-I (Stokin et al., 2005).

Aberrant p25/Cdk5 activity also modulates APP processing, as evidenced by enhanced BACE1 protein levels and $\beta$ APP-cleavage products found in the p $25 \mathrm{Tg}$ mouse models. These results are consistent with studies demonstrating that BACE1 expression is increased in the frontal cortex of human $\mathrm{AD}$ patients and correlates with increased BACE1 enzymatic activity and $\mathrm{A} \beta$ production (Fukumoto et al., 2002). APP phosphorylation may also affect its interaction with the APP-processing secretases. It has been proposed that Thr668 phosphorylation affects the endocytic trafficking of APP to facilitate the $\beta$-secretase cleavage of APP and increase $A \beta$ generation (Lee et al., 2003). Consistent with this notion, the p25 Tg mice do indeed exhibit increased phosphorylation of APP at Thr668 (Cruz et al., 2003), which can influence $\mathrm{A} \beta$ generation (Lee et al., 2003). Conversely, $\mathrm{A} \beta$ can induce conversion of p35 to p25 (Lee et al., 2000); these reciprocal findings suggest that a vicious feedforward loop between p25/Cdk5 and $\mathrm{A} \beta$ may ultimately result in pathological events that are associated with $\mathrm{AD}$.

In summary, our study outlines a novel mechanism for $\mathrm{AD}$ C-terminal fragments.
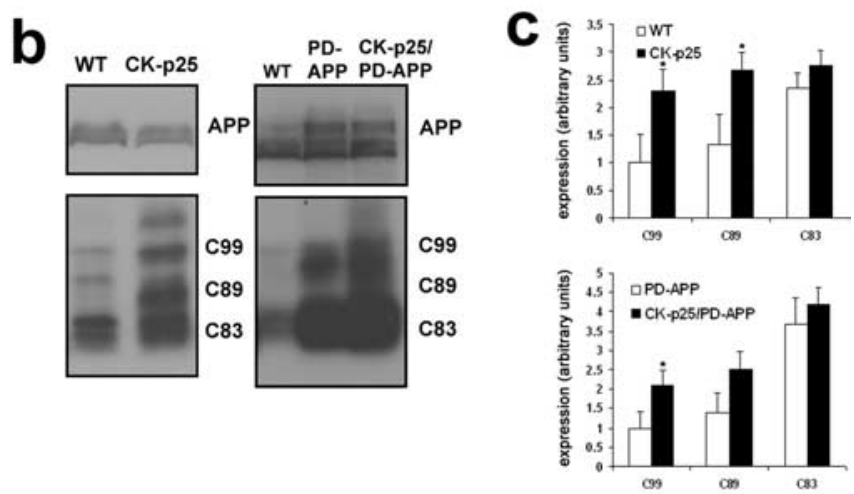

e
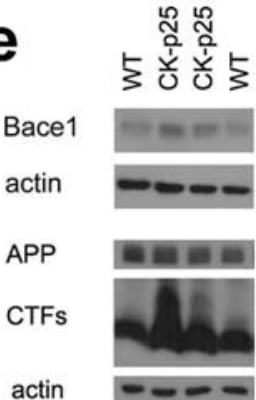

actin

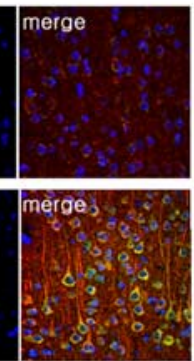

Figure 4. Enhanced BACE1 and $\beta$-secretase processing of APP in p25 Tg mice. $\boldsymbol{a}$, Increased BACE1 expression was shown by immunoblot analysis of RIPA-soluble forebrain extracts from 2 week induced CK-p25 mice. Data are mean \pm SEM values for WT (bottom) $C 99$ intensities. Data are mean \pm SEM values; $n=3$ for each genotype. by immunohistochemical analyses. Shown is a representative image from the cortex of a 2 week induced CK-p25 mouse. $\boldsymbol{e}$, BACE1 and C-terminal APP fragments are concomitantly increased at 5 weeks of induction. DAPI, $4^{\prime}, 6^{\prime}$-Diamidino-2-phenylindole; CTF,

pathogenesis that mechanistically links $\mathrm{p} 25 / \mathrm{Cdk} 5$ deregulation to $\mathrm{A} \beta$ upregulation and intraneuronal $\mathrm{A} \beta$ accumulation. Given these findings and the mounting evidence for the direct involvement of $\mathrm{p} 25 / \mathrm{Cdk} 5$ in the development of neurodegeneration, our results provide a strong impetus to develop therapeutic strategies to specifically inhibit p25/Cdk5-mediated events that lead to AD neuropathology.

\section{References}

Beglopoulos V, Sun X, Saura CA, Lemere CA, Kim RD, Shen J (2004) Reduced beta-amyloid production and increased inflammatory responses in presenilin conditional knock-out mice. J Biol Chem 279:46907-46914.

Billings LM, Oddo S, Green KN, McGaugh JL, Laferla FM (2005) Intraneuronal Abeta causes the onset of early Alzheimer's disease-related cognitive deficits in transgenic mice. Neuron 45:675-688.

Casas C, Sergeant N, Itier JM, Blanchard V, Wirths O, van der Kolk N, Vingtdeux V, van de Steeg E, Ret G, Canton T, Drobecq H, Clark A, Bonici B, Delacourte A, Benavides J, Schmitz C, Tremp G, Bayer TA, Benoit P, Pradier L (2004) Massive CA1/2 neuronal loss with intraneuronal and $\mathrm{N}$-terminal truncated Abeta42 accumulation in a novel Alzheimer transgenic model. Am J Pathol 165:1289-1300.

Cruz JC, Tseng HC, Goldman JA, Shih H, Tsai LH (2003) Aberrant Cdk5 activation by $\mathrm{p} 25$ triggers pathological events leading to neurodegeneration and neurofibrillary tangles. Neuron 40:471-483.

Ferreira A, Caceres A, Kosik KS (1993) Intraneuronal compartments of the amyloid precursor protein. J Neurosci 13:3112-3123.

Fischer A, Sananbenesi F, Pang PT, Lu B, Tsai LH (2005) Opposing roles of transient and prolonged expression of p25 in synaptic plasticity and hippocampus-dependent memory. Neuron 48:825-838.

Fukumoto H, Cheung BS, Hyman BT, Irizarry MC (2002) Beta-secretase 
protein and activity are increased in the neocortex in Alzheimer disease. Arch Neurol 59:1381-1389.

Games D, Adams D, Alessandrini R, Barbour R, Berthelette P, Blackwell C, Carr T, Clemens J, Donaldson T, Gillespie F, Guido T, Hagopian S, Johnson-Wood K, Khan K, Lee M, Leibowitz P, Lieberburg I, Little S, Masliah E, McConlogue L, et al. (1995) Alzheimer-type neuropathology in transgenic mice overexpressing V717F beta-amyloid precursor protein. Nature 373:523-527.

Gotz J, Chen F, van Dorpe J, Nitsch RM (2001) Formation of neurofibrillary tangles in P301l tau transgenic mice induced by Abeta 42 fibrils. Science 293:1491-1495.

Gouras GK, Tsai J, Naslund J, Vincent B, Edgar M, Checler F, Greenfield JP, Haroutunian V, Buxbaum JD, Xu H, Greengard P, Relkin NR (2000) Intraneuronal Abeta42 accumulation in human brain. Am J Pathol 156:15-20.

Haass C, Koo EH, Mellon A, Hung AY, Selkoe DJ (1992) Targeting of cellsurface beta-amyloid precursor protein to lysosomes: alternative processing into amyloid-bearing fragments. Nature 357:500-503.

Kayed R, Head E, Thompson JL, McIntire TM, Milton SC, Cotman CW, Glabe CG (2003) Common structure of soluble amyloid oligomers implies common mechanism of pathogenesis. Science 300:486-489.

LaFerla FM, Tinkle BT, Bieberich CJ, Haudenschild CC, Jay G (1995) The Alzheimer's A beta peptide induces neurodegeneration and apoptotic cell death in transgenic mice. Nat Genet 9:21-30.

Lee KY, Clark AW, Rosales JL, Chapman K, Fung T, Johnston RN (1999) Elevated neuronal Cdc2-like kinase activity in the Alzheimer disease brain. Neurosci Res 34:21-29.

Lee MS, Kwon YT, Li M, Peng J, Friedlander RM, Tsai LH (2000) Neurotoxicity induces cleavage of p35 to p 25 by calpain. Nature 405:360-364.

Lee MS, Kao SC, Lemere CA, Xia W, Tseng HC, Zhou Y, Neve R, Ahlijanian MK, Tsai LH (2003) APP processing is regulated by cytoplasmic phosphorylation. J Cell Biol 163:83-95.

Lewis J, Dickson DW, Lin WL, Chisholm L, Corral A, Jones G, Yen SH, Sahara N, Skipper L, Yager D, Eckman C, Hardy J, Hutton M, McGowan E (2001) Enhanced neurofibrillary degeneration in transgenic mice expressing mutant tau and APP. Science 293:1487-1491.

Masliah E, Sisk A, Mallory M, Mucke L, Schenk D, Games D (1996) Com- parison of neurodegenerative pathology in transgenic mice overexpressing V717F $\beta$-amyloid precursor protein and Alzheimer's disease. J Neurosci 16:5795-5811.

Morfini G, Szebenyi G, Brown H, Pant HC, Pigino G, DeBoer S, Beffert U, Brady ST (2004) A novel CDK5-dependent pathway for regulating GSK3 activity and kinesin-driven motility in neurons. EMBO J 23:2235-2245.

Noble W, Olm V, Takata K, Casey E, Mary O, Meyerson J, Gaynor K, LaFrancois J, Wang L, Kondo T, Davies P, Burns M, Veeranna, Nixon R, Dickson D, Matsuoka Y, Ahlijanian M, Lau LF, Duff K (2003) Cdk5 is a key factor in tau aggregation and tangle formation in vivo. Neuron 38:555-565.

Oddo S, Caccamo A, Shepherd JD, Murphy MP, Golde TE, Kayed R, Metherate R, Mattson MP, Akbari Y, LaFerla FM (2003) Triple-transgenic model of Alzheimer's disease with plaques and tangles: intracellular Abeta and synaptic dysfunction. Neuron 39:409-421.

Patrick GN, Zukerberg L, Nikolic M, de la Monte S, Dikkes P, Tsai LH (1999) Conversion of p 35 to p25 deregulates Cdk5 activity and promotes neurodegeneration. Nature 402:615-622.

Selkoe DJ, Schenk D (2003) Alzheimer's disease: molecular understanding predicts amyloid-based therapeutics. Annu Rev Pharmacol Toxicol 43:545-584.

Stokin GB, Lillo C, Falzone TL, Brusch RG, Rockenstein E, Mount SL, Raman R, Davies P, Masliah E, Williams DS, Goldstein LS (2005) Axonopathy and transport deficits early in the pathogenesis of Alzheimer's disease. Science 307:1282-1288.

Swatton JE, Sellers LA, Faull RL, Holland A, Iritani S, Bahn S (2004) Increased MAP kinase activity in Alzheimer's and Down syndrome but not in schizophrenia human brain. Eur J Neurosci 19:2711-2719.

Tsai LH, Delalle I, Caviness Jr VS, Chae T, Harlow E (1994) p35 is a neuralspecific regulatory subunit of cyclin-dependent kinase 5. Nature 371:419-423.

Van Dorpe J, Smeijers L, Dewachter I, Nuyens D, Spittaels K, Van Den Haute C, Mercken M, Moechars D, Laenen I, Kuiperi C, Bruynseels K, Tesseur I, Loos R, Vanderstichele H, Checler F, Sciot R, Van Leuven F (2000) Prominent cerebral amyloid angiopathy in transgenic mice overexpressing the London mutant of human APP in neurons. Am J Pathol 157:12831298. 